\title{
Locus heterogeneity in autosomal dominant congenital external ophthalmoplegia (CFEOM)
}

\author{
G C M Black, R Perveen, E Hatchwell, A Reck, J Clayton-Smith
}

\begin{abstract}
Congenital external ophthalmoplegia (CFEOM) is an uncommon autosomal dominant condition that has previously been mapped to the pericentromeric region of chromosome 12 in seven families with no evidence of locus heterogeneity. We report three families with typical CFEOM. One family does not map to this region of chromosome 12 or to other chromosomal locations implicated in disorders of lid or ocular movement. Recombinants in two CFEOM families potentially help to reduce the size of the candidate region on chromosome 12 . $(\mathcal{M}$ Med Genet 1998;35:985-988)
\end{abstract}

Keywords: heterogeneity; chromosome 12; CFEOM

Congenital external ophthalmoplegia (CFEOM, MIM 135700) is an uncommon, highly penetrant autosomal dominant disorder characterised by bilateral, non-progressive ptosis and generalised external ophthalmoplegia. Laughlin ${ }^{1}$ characterised the syndrome as a congenital condition encompassing (1) extraocular muscle fibrosis, (2) adhesions between the muscles, Tenon's capsule (one of the anterior tissues of the eye), and the globe, (3) absence of elevation or depression of the eyes, (4) little or no horizontal movement, (5) fixation of the eyes $20-30^{\circ}$ below the horizontal, and (6) blepharoptosis with chin elevation. ${ }^{2}$ Residual ocular movements are often abnormal $^{3}$ and there may be associated amblyopia. There is occasionally evidence of additional neurological features, including mild facial weakness. ${ }^{4}$

Genetic analysis among families with an apparently fully penetrant form of the disorder showed linkage to markers within a region of approximately $3 \mathrm{cM}$ around the centromere of chromosome 12, with no evidence of locus heterogeneity. ${ }^{45}$ The closest flanking markers were D12S1584 on $12 p$ and D12S1668 on 12q. As yet, no obvious candidate genes have been identified within this region. A second form of CFEOM, associated with globes frozen in extreme abduction, which is inherited in an autosomal recessive fashion, has recently been linked to chromosome $11 \mathrm{q} 13 .^{6}$ A potentially related locus, responsible for autosomal dominant ptosis with normal extraocular movements, has been identifed on chromosome 1p32-p34.1. ${ }^{7}$

We have identified three families in which affected members have the classical phenotype of autosomal dominant CFEOM and tested them for linkage to the pericentromeric region of chromosome 12. In one family we have shown linkage exclusion for this region, as well as those for autosomal recessive CFEOM and autosomal dominant ptosis. This indicates that heterogeneity exists within dominant forms of the condition.

\section{Materials and methods \\ FAMILIES}

Three families were ascertained through probands with classical CFEOM (fig 1): congenital, bilateral ptosis associated with
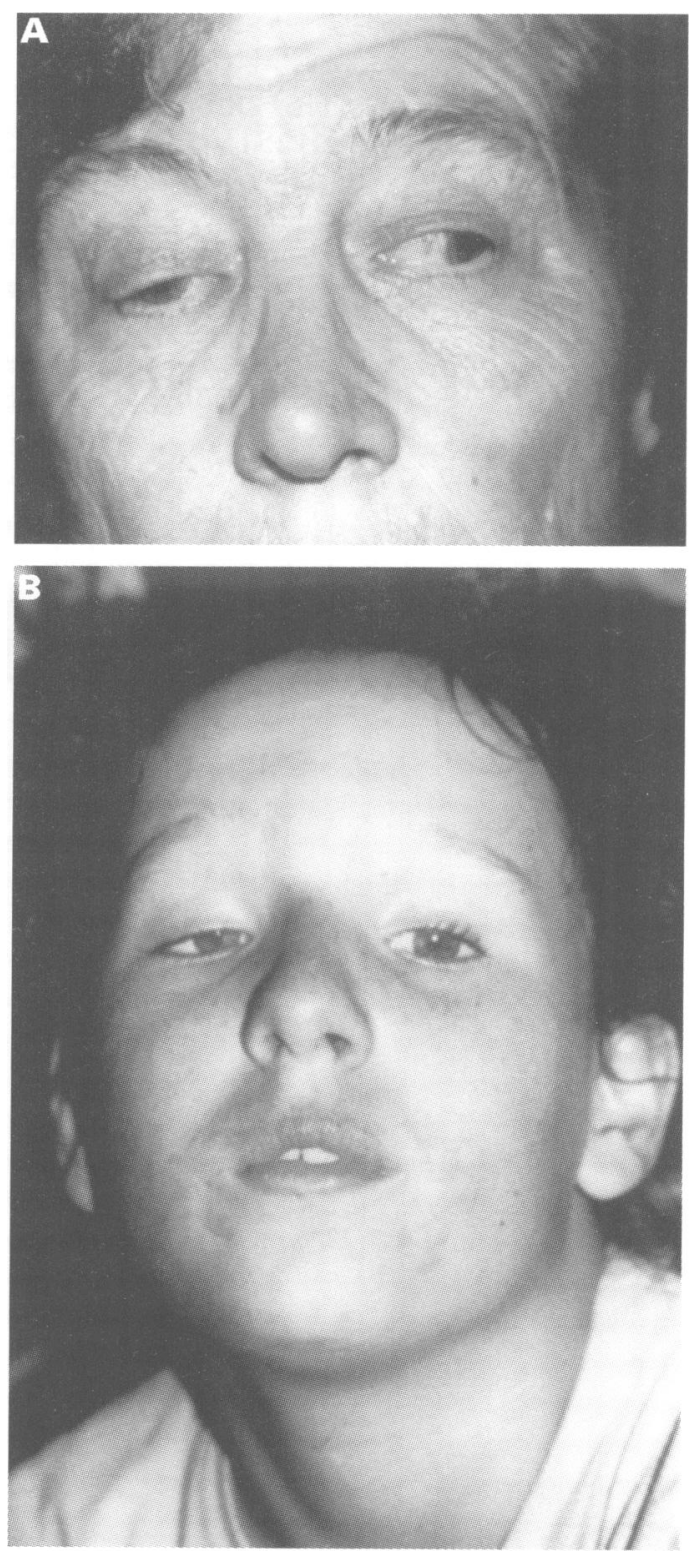

Figure 1 Clinical appearance of patients with CFEOM from family 1. (A) Patient I.2. Note failure of elevation, divergent squint, and bilateral, asymmetrical ptosis. (B) Patient III. 1. Note "chin up" head posture with bilateral, asymmetrical ptosis and squint. 
Table 1 Clinical manifestations of CFEOM in affected members of families 1-3

\begin{tabular}{|c|c|c|c|c|c|c|c|c|}
\hline Family & Subject & $\begin{array}{l}\text { Non-progressive } \\
\text { phenotype }\end{array}$ & $\begin{array}{l}\text { Fixation below } \\
\text { horizontal }\end{array}$ & Bilateral ptosis & $\begin{array}{l}\text { Reduced vert } \\
\text { ocular movements }\end{array}$ & $\begin{array}{l}\text { Reduced horiz } \\
\text { ocular movements }\end{array}$ & Chin elevation & Strabismus \\
\hline \multirow[t]{7}{*}{ Family 1} & 1.2 & + & + & + & + & + & + & Exotropia \\
\hline & II. 1 & + & + & + & + & + & + & Exotropia \\
\hline & II. 2 & + & + & + & + & + & + & Exotropia \\
\hline & II. 5 & + & + & + & + & + & + & Exotropia \\
\hline & II.7 & + & + & + & + & + & + & Exotropia \\
\hline & III.1 & + & + & + & + & + & + & Exotropia \\
\hline & III. 2 & + & + & + & + & + & + & Exotropia \\
\hline \multirow[t]{3}{*}{ Family 2} & II. 2 & + & + & + & + & + & + & Esotropia \\
\hline & III. 3 & + & + & + & + & Minimal & + & Exotropia \\
\hline & III.4 & + & + & + & + & Minimal & + & Esotropia \\
\hline \multirow[t]{4}{*}{ Family 3} & I. 2 & + & + & Minimal & + & + & + & Exotropia \\
\hline & II. 1 & + & + & + & + & + & + & Exotropia \\
\hline & II. 2 & + & + & + & + & + & + & NR \\
\hline & II. 3 & + & NR & + & + & + & + & NR \\
\hline
\end{tabular}

$\mathrm{NR}=$ not recorded

restricted ocular movement, infraducted globes, and strabismic position. All subjects included in the molecular analyses were examined by one of the authors. Blood samples were obtained from family members and DNA extracted using conventional methods.

PCR GENOTYPING

The chromosome 12 microsatellite markers D12S1631 (Afma288wd5), D12S345 (AFM296yg5), D12S331 (AFM092wd11), D12S1048 (C-ATA29H01), D12S1584 (AFM136xf6), and D12S1668 (AFMb320 wd9) were used for haplotype analysis of the region. Analysis of $11 \mathrm{p} 13$ (CFEOM2) was performed using the markers D11S4076 (AFMa356yg5), D11S4139 (AFMb038yb9),

Family 1

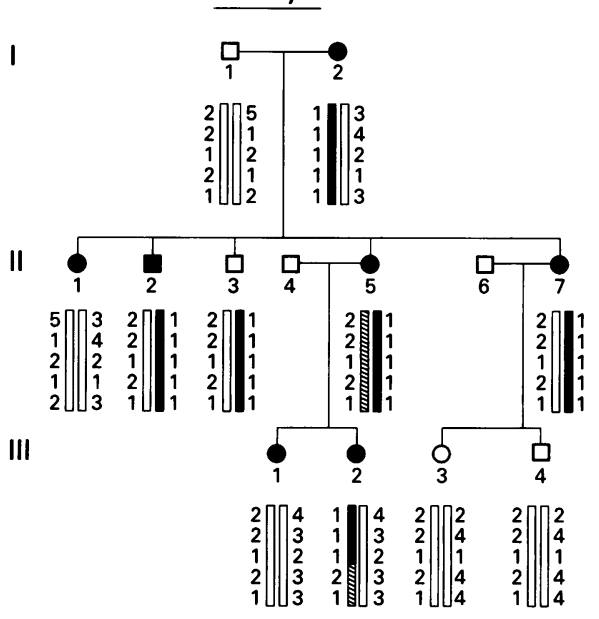

and D11S916 (AFM185ya1) and of chromosome 1p32-34.1 (hereditary autosomal dominant ptosis) with the markers D1S447 (AFM024xd2), D1S2677 (AFM244yf5), and D1S197. PCR was performed using the primers previously described ${ }^{8}$ with 50 ng DNA, 1 $\mathrm{ml} \mathrm{PCR} \mathrm{buffer}\left(166 \mathrm{mmol} / 1\left(\mathrm{NH}_{4}\right)_{2} \mathrm{SO}_{4}, 670\right.$ $\mathrm{mmol} / 1$ Tris- $\mathrm{HCl}, \mathrm{pH} 8,67 \mathrm{mmol} / 1 \mathrm{MgCl}_{2}, 1.7$ $\mathrm{mg} / \mathrm{ml} \mathrm{BSA}$ ), $200 \mathrm{mmol} / 1$ each $\mathrm{dNTP}, 1 \mathrm{pmol}$ of each primer, and $0.5 \mathrm{U}$ of Taq polymerase. An initial denaturation step $\left(94^{\circ} \mathrm{C}\right.$ for three minutes) was followed by 30 cycles of denaturation $\left(94^{\circ} \mathrm{C}\right.$ for 50 seconds), annealing $\left(57^{\circ} \mathrm{C}\right.$ for 50 seconds), and extension $\left(72^{\circ} \mathrm{C}\right.$ for 50 seconds), and a final three minutes at $72^{\circ} \mathrm{C}$. Products were run on $8 \%$ polyacrylamide gels and silver stained according to standard methods.

Family 2

I

॥

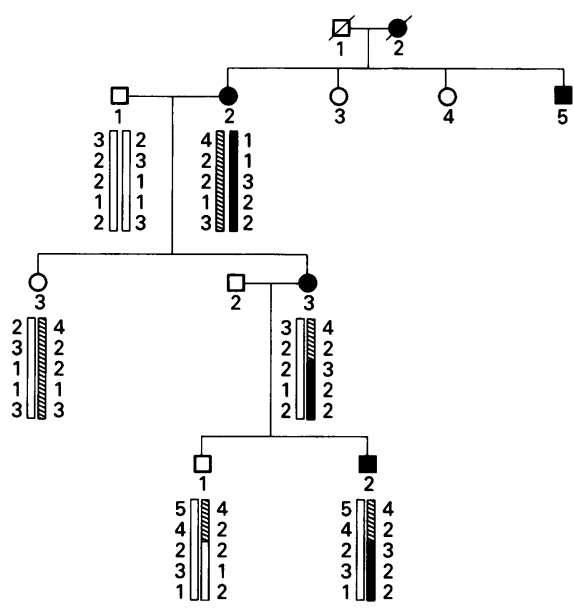

Family 3

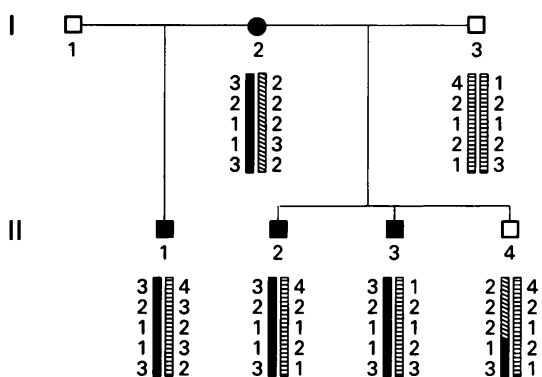

Figure 2 Microsatellite analysis of families 1-3. Haplotypes indicated from top to bottom, markers D12S1631, D12S345, D12S331, D12S1048, and D12S1668. 
Table 2 Two point lod scores for CFEOM in family 1. (A) Chromosome 12 markers spanning AD CFEOM critical region. (B) Chromosome 11 markers from $A R$ CFEOM region. (C) Chromosome 1 markers spanning $A D$ ptosis critical region

\begin{tabular}{lllll}
\hline \multicolumn{5}{c}{ Lod score v CFEOM } \\
\hline A & Locus & $\theta=0$ & $\theta=0.02$ & $\theta=0.04$ \\
& D12S1631 & $-\infty$ & -2.73 & -1.87 \\
& D12S345 & $-\infty$ & -2.73 & -1.87 \\
& D12S1048 & $-\infty$ & .21 & -1.62 \\
& D12S1668 & $-\infty$ & -2.21 & -1.62 \\
\hline \multicolumn{5}{c}{ Lod score $v$ CFEOM } \\
\hline B & Locus & $\theta=0$ & $\theta=0.02$ & $\theta=0.04$ \\
& D11S4076 & $-\infty$ & -3.91 & -2.15 \\
& D11S4139 & $-\infty$ & -5.01 & -3.82 \\
& D11S916 & $-\infty$ & -4.7 & -3.53 \\
\hline \multicolumn{5}{c}{ Lod score v CFEOM } \\
& & & \\
\hline C & Locus & $\theta=0$ & $\theta=0.01$ \\
& D1S447 & $-\infty$ & -1.44 \\
& D1S2677 & $-\infty$ & -1.71 \\
& D1S197 & $-\infty$ & -1.62 \\
\hline
\end{tabular}

LINKAGE ANALYSIS

Linkage analysis was performed using the MLINK and LINKMAP programs and using the published genetic distances. ${ }^{89}$

\section{Results}

CLINICAL PHENOTYPES

The pedigrees of families CFEOM1-3 are shown in fig 2 . As others have described, ${ }^{4}$ there is variability, both within and between families, in the degree and symmetry of ptosis and strabismus and the degree to which movement of individual muscles was affected. However, affected subjects in all three families fitted the clinical description of classical CFEOM: congenital, non-progressive problems associated with bilateral ptosis, chin elevation, infraducted globes with reduced/absent elevation, reduced horizontal movements, and a strabismic position (table 1). No unaffected subject had any signs of the disorder. No affected subject had any additional neurological features, although affected subject II. 5 in family CFEOM1 had mild corectopia (distorted pupils) and a sectoral cortical cataract, which had no effect on vision at the age of 36 . No other member of the family had similar clinical signs.

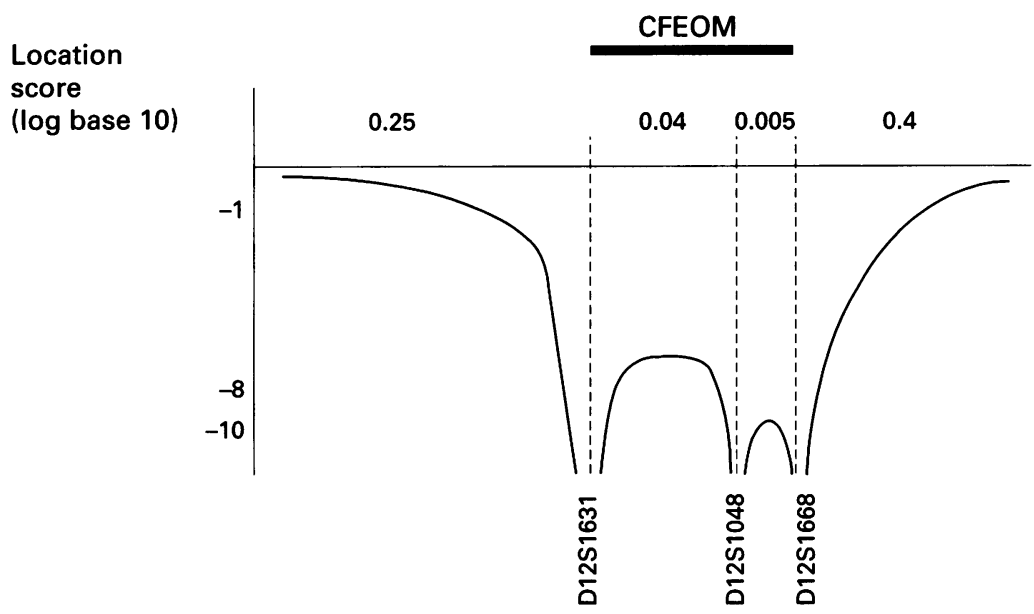

Figure 3 Multipoint analysis of family CFEOM1: exclusion data from pericentromeric region of chromosome 12.
GENETIC ANALYSIS

The results of microsatellite analysis of the three families are shown in fig 2. In family 1 each marker from chromosome 12 gives lod scores <-2 (table 2) and LINKMAP analysis excludes the complete candidate region (fig 3). Microsatellite analysis of the candidate regions of chromosome 11q13 (CFEOM2) and 1p32p34.1 (hereditary congenital ptosis) also excluded these regions (table 2 ).

Haplotype analysis was performed in families 2 and 3 using chromosome 12 markers. In family 2 the affected subject III. 3 showed a recombination between D12S345 and D12S331; CFEOM segregates with the 12q markers D12S331, D12S1048, and D12S1668. In family 3 the unaffected subject II. 4 inherited a chromosome with a recombination between D12S331 and D12S1048; the normal allele of CFEOM segregates with D12S331 and the 12p markers (assuming full penetrance of CFEOM).

\section{Discussion}

Both for counselling and for gene cloning, it is important to know whether the condition under study is genetically and clinically homogeneous. Family 1 provides clear evidence of locus heterogeneity in autosomal dominant CFEOM. In this family, which is of AngloSaxon origin, the disease does not map to the previously defined candidate region around the centromere of chromosome 12 , nor to regions implicated in the aetiology of the related disorders autosomal recessive CFEOM (CFEOM2) and autosomal dominant congenital ptosis.

The families studied by Engle et $a l^{45}$ were limited to those with "classical CFEOM". However, other varying clinical manifestations, including isolated horizontal or inferior rectus muscle fibrosis associated with blepharoptosis, ${ }^{9}$ are described and raise the question of heterogeneity. The affected subjects in family 1 fit the classical phenotype of CFEOM although it is interesting to note, as with subjects with CFEOM2, all had marked exotropia. In addition one had ectopic pupils and cortical cataracts at the age of 36 . In 1976, McPherson et $a l^{10}$ described a mother and two sons who had ptosis, extraocular muscle abnormalities, and ectopic pupils. From the clinical description, the ocular motility defect in that family has parallels with CFEOM; it is possible that this represents a phenotypic distinction of a condition similar to classical CFEOM but with ocular manifestations.

In preparation for positional cloning, YAC contigs have been assembled for the regions immediately flanking the chromosome 12 pericentromeric satellite regions. ${ }^{5}$ Although genetically the candidate region is only $2-3 \mathrm{cM}$, physical mapping suggests it covers around 6.5 $\mathrm{Mb}$, the discrepancy presumably because of suppression of recombination around the centromere. Clearly it will be important to find recombinants that reduce the size of the candidate region. If one were confident of locus homogeneity and full penetrance, the recombinants in families 3 and 4 could be used to narrow down the candidate region to 
D12S345-D12S1048. In practice, they underline the problems of relying on key recombinants in families too small for independent confirmation of linkage, a situation that is likely to arise with a rare condition like CFEOM.

Therefore, we suggest that results of linkage analysis in small families with CFEOM be treated with caution. In counselling, discussion with families should raise the possibilities of heterogeneity. Finally, a detailed ophthalmic assessment may facilitate the identification of a subgroup of patients with non-classical CFEOM, which is not linked to the pericentromeric region of chromosome 12 .

$R P$ is supported by the Birth Defects Foundation, GB is supported by the Wellcome Trust (Ref 051390/Z).

1 Laughlin RC. Congenital fibrosis of the extraocular muscles: a report of six cases. Am $\mathcal{F}$ Ophthalmol 1956;41:432-8.

2 Hiatt RL, Hall AA. General fibrosis syndrome. Acta Ophthalmol (Copenh) 1983;46:469-76.
3 Brodsky MC, Pollock SC, Buckley EG. Neural misdirection in congenital ocular fibrosis syndrome: implications and pathogenesis. Paediatr Ophthalmol Strabismus 1989;26:15961.

4 Engle EC, Kunkel LM, Specht LA, Beggs AH. Mapping a gene for congenital fibrosis of the extraocular muscles to the centromeric region of chromosome 12. Nat Genet the centromeric

5 Engle EC, Marondel I, Houtman WA, et al. Congenital fibrosis of the extraocular muscles (autosomal dominant congenital external ophthalmoplegia): genetic homogeneity, linkage refinement and physical mapping on chromosome 12. Am $₹$ Hum Genet 1995;57:1086-94.

6 Wang SM, Zwaan J, Mullaney PB, et al. Congenital fibrosis of the extraocular muscles type 2 , an inherited exotropic strabismus fixus, maps to distal 11q13. Am f Hum Genet 1998;63:517-25.

7 Engle EC, Castro AE, Macy ME, Knoll JHM, Beggs AH. A gene for isolated congenital ptosis maps to a 3-cM region within 1p32-p34.1. Am f Hum Genet 1997;60:1150-7.

8 Dib C, Faure S, Fizames C, et al. A comprehensive genetic map of the human genome based on 5,264 microsatellites. Nat Genet 1996;380:152-4.

9 Apt L, Axelrod RN. Generalised fibrosis of the extraocular muscles. Am 7 Ophthalmol 1978;85:822-9.

10 McPherson E, Robertson C, Cammarano A, Hall J. Dominantly inherited ptosis, strabismus and ectopic pupils. Clin Genet 1976;10:21-6. 